\title{
Hormonal control of brood care and social status in a cichlid fish with brood care helpers
}

\author{
Nicole Bender ${ }^{\text {a,*}}$, Zina Heg-Bachar ${ }^{\text {a }}$, Rui F. Oliveira ${ }^{b}$, Adelino V.M. Canario ${ }^{c}$, Michael Taborsky ${ }^{\text {a }}$ \\ ${ }^{a}$ Behavioural Ecology, Ethologische Station Hasli, Institute of Zoology, University of Bern, Wohlenstrasse 50a, Hinterkappelen, CH-3032, Switzerland \\ ${ }^{\mathrm{b}}$ Unidade de Investigação em Eco-Etologia, Instituto Superior de Psicologia Aplicada, Rua Jardim do Tabaco 34, 1149-041 Lisbon, Portugal \\ ${ }^{\mathrm{c}}$ Centro de Ciências do MAR (CCMar), Universidade to Algarve, Campus de Gambelas, 8000-117 Faro, Portugal
}

Received 9 November 2006; received in revised form 13 November 2007; accepted 6 February 2008

\begin{abstract}
We studied the role of steroid hormones for parental and alloparental brood care and social status in a cooperatively breeding fish. We measured excretion levels of testosterone and 11-ketotestosterone in males, estradiol-17 $\beta$ in females and cortisol in both sexes at different stages of the breeding cycle, and compared these values to data measured in non-reproductive fish.

Brood care behaviour does not seem to relate to steroid hormone excretion levels in this species. Steroid hormones varied with social status, however. Non-territorial male aggregation members, for example, showed high testosterone and low 11-ketotestosterone excretion levels, suggesting that they might pursue a "stand-by strategy" for breeding to react quickly if an occasion for breeding arises. Cortisol excretion levels are high in juvenile helpers compared to same-size aggregation members, suggesting higher stress levels in subordinate members of reproductive groups. This is the first study assessing if steroid hormone control mechanisms are involved in brood care and social roles in a cooperatively breeding fish.

(C) 2008 Elsevier Inc. All rights reserved.
\end{abstract}

Keywords: Neolamprologus pulcher; Alloparental care; Cooperative breeding; Alternative mating tactics; Hormonal regulation; Advanced sociality

\section{Introduction}

In many highly social vertebrates subordinate helpers assist breeders in offspring care. Such alloparental care has been studied extensively in several mammals and birds and in some fish [1-4]. However, the hormonal control mechanisms involved are still poorly understood [5-9].

In fish, hormonal control of brood care behaviour has been studied in male and female parents of several species [10-16]. The most important hormones involved in paternal behaviour are prolactin [17-19] and the androgens testosterone and 11 -ketotestosterone $[11,12]$. In females, brood care behaviour is apparently controlled mainly by estrogens, but progestogins, corticosteroids and prolactin are also involved [11]. Furthermore, other hormones have been suggested to be of importance for brood care in parents like growth hormone and progestogins

\footnotetext{
* Corresponding author.

E-mail address: nbender@ispm.unibe.ch (N. Bender).
}

in female mouthbrooders [16] and progestogins in males $[20,21]$. In the regulation of brood care, like in other functional contexts, hormones and behaviour interact in a bidirectional and reciprocal way following complex rules [22-26].

In the present paper we studied the role of steroid hormones in the control of parental and alloparental brood care behaviour in a cooperatively breeding fish. This is the first study to investigate how different hormones control brood care and social roles in fish with brood care helpers and shall contribute to our general understanding of hormonal control mechanisms and evolution of alloparental brood care behaviour in vertebrates.

Neolamprologus pulcher, a substrate breeding cichlid endemic to Lake Tanganyika, East Africa, has the most highly advanced social system of any fish species known to date $[1,27,28]$. In this species, breeders and helpers of both sexes, including mature and immature, related and unrelated fish share in cleaning and defending the brood and territory. This species breeds throughout the year with no seasonality and the males can spawn with more than one female in neighbouring territories [1,2,29-34]. 
Von Siemens [35] showed that in this species brood care propensity depends on different social and behavioural factors in breeders and helpers, which suggests different hormonal control mechanisms.

In an accompanying study we found no evidence for a positive effect of prolactin on parental or alloparental care in $N$. pulcher [36]. Furthermore, several studies showed similar androgen levels in male breeders and male helpers of $N$. pulcher $[5,37]$, which probably relates to the fact that in this species male helpers may participate in reproduction [38,39].

Cortisol is a "stress hormone" released into the blood after activation of the hypothalamus-pituitary-adrenal axis. Cortisol has a range of different physiological effects like energy mobilisation, increase of the cardiovascular tone and the regulation of the immune system. The relationship between social status and cortisol levels is complex, depending on the social system of the species considered. Therefore, the investigation of the role of cortisol in brood care behaviour of $N$. pulcher is one important aim of this study.

In the present study, we measured excretion levels of the steroid hormones testosterone and 11-ketotestosterone in males, estradiol-17 $\beta$ in females and cortisol in all fish at different stages of the breeding cycle with a non-invasive technique, and we compared these values to measures obtained from non-reproducing fish of matched size range. Non-reproducing fish are fish of both sexes and of all age classes living in large groups without territory (i.e. in aggregations). The adult aggregation fish do not reproduce, but are able to do so within 3-7 days if provided with a territory and a mate. The status of a fish is therefore dependent on the actual ecological circumstances and can change in either direction within days.

In family group members we expected to find higher levels of key hormones in the presence of a brood compared to the situation without actual brood. This prediction applies especially to breeder females, as males can breed with several females at different stages of the breeding cycle concurrently. Furthermore, we predicted to find differences in sex hormone levels between breeders and helpers (but no difference in androgens between male breeders and adult male helpers, as outlined above) and in cortisol levels between the sexes. Reproductively active fish should show higher sex steroid levels than non-reproducing aggregation fish. Cortisol levels reflect stress and therefore should differ between fish of different social status.

\section{Methods}

\subsection{Experimental design}

Fish were kept at the Ethologische Station "Hasli", Institute of Zoology, University of Bern. The eight experimental family groups were combinations of a breeding pair (males: range of standard length $(\mathrm{SL})=54.5-76 \mathrm{~mm}$, mean $=71.6$; females: $\mathrm{SL}=61-66.5 \mathrm{~mm}$, mean $=63.1$ ), two adult helpers of both sexes (male helpers $(\mathrm{SL}=41-70 \mathrm{~mm}$, mean $=53.1)$, female helpers $(\mathrm{SL}=42-55.5 \mathrm{~mm}$, mean $=51.8))$ and a sexually immature helper $(\mathrm{SL}=29-36 \mathrm{~mm}$, mean $=32.4)$. These groups were not combined from related individuals, which corresponds to the natural situation [30]. Range of body masses (BM): males: $\mathrm{BM}=4.714-12.617 \mathrm{~g}$, mean $=10.924 \mathrm{~g}$; females: $\mathrm{BM}=6.158$ $7.671 \mathrm{~g}$, mean $=7.029 \mathrm{~g}$; male helpers: $\mathrm{BM}=1.741-9.49 \mathrm{~g}$, mean $=4.43 \mathrm{~g}$; female helpers: $\mathrm{BM}=2.062-3.922 \mathrm{~g}$, mean $=4.127 \mathrm{~g}$; immature helper: $\mathrm{BM}=0.749-1.359 \mathrm{~g}$, mean $=0.965 \mathrm{~g}$. The sex of immature fish could not be determined reliably. These family groups were introduced into tanks of 601 , structured with a layer of sand and two halves of a bottomless flowerpot as breeding shelters. Non-reproducing aggregations consisted of adults of both sexes (males: $\mathrm{SL}=57.5$ $71.5 \mathrm{~mm}$, mean $=66.4 ; \mathrm{BM}=5.613-10.681 \mathrm{~g}$, mean $=8.575 \mathrm{~g}$; females: $\mathrm{SL}=57.5-71.5 \mathrm{~mm}$, mean $=65.9 ; \mathrm{BM}=5.286-$ $12.566 \mathrm{~g}$, mean $=8.345 \mathrm{~g})$ and juvenile fish $(\mathrm{SL}=27.5-$ $30.5 \mathrm{~mm}$, mean $=28.6 ; \mathrm{BM}=0.522-0.797 \mathrm{~g}$, mean $=0.636 \mathrm{~g}$ ). These mixed non-reproducing groups were kept in tanks of 200 or 4001 depending on group size (30-60 fish per group), which contained no shelters but only a layer of sand. Shelters were avoided to prevent territoriality and reproduction. All fish in this study were fed, observed and manipulated always at the same time of day during the observation period to rule out a confounding effect of potential diurnal fluctuations of hormone levels. The social status, sex and size of each fish were determined before each manipulation. All manipulations of fish adhered to the official rules and regulations of Switzerland of handling experimental animals and were approved by the veterinary control agency of the Kanton Bern.

The control group consisted of the non-reproductive aggregations. These fish were expected to show baseline levels of sex steroid hormones and cortisol, as they were not exposed to a potential influence of reproductive stimuli, a strong hierarchy or the presence of a territory or brood. Above ca. $3.5 \mathrm{~cm}$ standard length these fish become sexually mature, but in aggregations they remain sexually inactive $[1,33]$. From each category of aggregation fish (males, females and juveniles) eight fish were randomly chosen and steroid hormones were collected as described below. In males, we measured testosterone and 11 -ketotestosterone, in females estradiol-17 $\beta$ and in all fish cortisol.

Within family groups we compared steroid levels with and without an own clutch present. We measured the same hormones in each category of fish as in the aggregation members. When eggs were laid in one of the experimental family groups, the hormone levels of all group members were determined, and then the clutch was removed. After six days the measurements were repeated to obtain basic hormone levels between two breeding cycles. As a second step, a foreign clutch was presented to these families outside of their breeding period (see below) and all members were observed to test if they showed brood care (fanning, cleaning eggs) or not (eating eggs). In fish that showed brood care, hormones were measured again.

Foreign test clutches were produced by $44 N$. pulcher families that were not part of the experiment. These families were provided with clear PET (polyethylene terephthalate) lining in their breeding shelters. Every morning the shelters were checked and linings with attached eggs were removed and replaced with new, clean ones. The collected linings with eggs were kept in separate tanks at $24{ }^{\circ} \mathrm{C}$ and were well aerated with air stones to avoid 
fungal growth. The clutches were divided by cutting the linings with scissors to standardize clutch size (20-50 eggs per clutch). Foreign test clutches were presented to test fish by attaching the egg bearing linings under flower pot halves, which were then placed in the test tanks instead of the breeding shelters for each observation period (30 min each). Eggs were counted before and after the experiment to determine if eggs were consumed during exposure. Eggs with fungal growth were removed before the experiment.

\subsection{Hormone assays}

Steroid hormone excretion levels were measured from fishholding water to allow repeated and non-invasive measurements in small fish [5,40,41]. Each fish was placed singly into a small volume of clean water (500 $\mathrm{ml}$ for juveniles, $1000 \mathrm{ml}$ for adults) for $1 \mathrm{~h}$. This water had the same composition as the fish's tank water and was taken from a special pool tank which had never contained fish. To avoid contamination, all materials used were washed with ethanol and distilled water before each measurement. After the experimental fish had been removed, the test water was filtered through paper filters (595 1/2 folded filters, $\varnothing$ $320 \mathrm{~mm}$; Schleicher \& Schuell) and then passed through a solidphase C18 extraction column (Sep Pak RP-18, Merck) to adsorb the steroids. These columns were frozen at $-20{ }^{\circ} \mathrm{C}$ until further processing. To preclude variance caused by potential diurnal hormone fluctuations, sampling always took place at the same time slot (between 11.00 and 13.00) and before feeding.

Fishes release several fractions of steroid hormones into the water. The free fraction is mainly released through the gills, the conjugated fractions through urine (sulphated fraction) and faeces (glucuronidated fraction) [42-44]. The hormone measurements were carried out following the procedures to measure steroids from fish-holding water described by Scott and Sorensen [43] and from fish urine described by Oliveira et al. [45]. Steroids were eluted from the C18 columns with ethanol. After evaporation of the ethanol with a stream of nitrogen, the residue was resuspended in a small volume of distilled water and the free, sulphated and glucuronidated fractions were extracted sequentially with diethyl ether before and after solvolysis and hydrolysis with glucuronidase [46]. Steroids were finally quantified by previously characterized radioimmunoassay: estradiol-17ß [47]; testosterone [48]; 11-ketotestosterone [49] and cortisol (ANTI-Cortisol, Research Diagnostics Inc [50]). The results of the different fractions were summed.

Several studies have validated the method of measuring excreted steroid hormones in fish-holding water [5,40-43]. Steroid excretion rates of goldfish (Carassius auratus) measured in holding water [43] matched well the blood plasma levels in fish receiving similar treatment [51]. Injecting Tilapia males (Oreochromis mossambicus) with luteinizing hormone-releasing hormone (LHRH), the excretion of testosterone and 11-ketotestosterone measured in fish-holding water increased as expected [40]. Separation of fish-holding water on thin-layer chromatography and assays of fractions thereby obtained confirmed the specificity of the antisera used to measure androgens in N. pulcher [5]. The details for antibodies' cross-reactivity have been described by Scott and co-workers [48]. This method has the advantage to be insensitive to short term fluctuations in hormone levels, as shown for example in plasma, because the steroid levels accumulated in water represent the hormones released over the last hours as an integral measure (e.g. [42]).

\subsection{Data analysis}

Rates of hormone excretion were calculated per hour and fish. Cortisol and estradiol-17 $\beta$ levels were ln-transformed to normalize the data. Following Sokal and Rohlf [52] seven outliers in total were detected and removed from the analyses in order to obtain normally distributed data. However, the removal of the outliers did not change the significance or direction of the results (data not shown). To calculate the relationship between hormones and status, univariate analyses of covariance were performed separately for each hormone, with mass included as covariate to correct for potential body mass effects. Multiple comparisons were adjusted according to the Benjamini and Hochberg adaptive approach to control for multiple testing [53].

The relationship between hormones and brood care was studied using a repeated measures univariate analysis of variance in which the repeated hormone levels of each fish family, once with eggs and once without, were compared. Similarly, in these repeated measures ANOVAs we did not include body mass as covariate, as comparisons were performed only within individuals. All statistical analyses were performed with SPSS 11.0 with alpha set at 0.05 , two-tailed.

\section{Results}

\subsection{1-ketotestosterone}

Overall, social status was significantly related to the rate of 11-ketotestosterone excretion (Table 1). Aggregation males

Table 1

ANCOVA table of factors affecting 11-ketotestosterone and testosterone levels in males, estradiol-17 $\beta$ levels in females and cortisol levels in all fish (estradiol$17 \beta$ and cortisol levels were $\ln$-transformed before analyses to meet the required test conditions)

\begin{tabular}{lllrl}
\hline Hormone & Factor & $F$ & $d f$ & $P$ \\
\hline 11-ketotestosterone & Status & 4.413 & 2 & $\mathbf{0 . 0 2 7}$ \\
& Mass & 0.222 & 1 & 0.643 \\
Testosterone & Error & & 19 & \\
& Status & 5.866 & 2 & $\mathbf{0 . 0 1}$ \\
& Mass & 0.011 & 1 & 0.917 \\
Estradiol-17ß & Error & & 19 & \\
& Status & 4.756 & 2 & $\mathbf{0 . 0 2 3}$ \\
& Mass & 1.145 & 1 & 0.300 \\
Cortisol & Status* mass & 4.541 & 2 & $\mathbf{0 . 0 2 6}$ \\
& Error & & 17 & \\
& Status & 1.775 & 2 & 0.179 \\
& Sex & 4.058 & 2 & $\mathbf{0 . 0 2 3}$ \\
& Mass & 0.002 & 1 & 0.96 \\
& Status* sex & 3.601 & 3 & $\mathbf{0 . 0 1 9}$ \\
& Error & & 53 & \\
\hline
\end{tabular}

Mass has been included as covariate to account for potential body mass effects on hormone levels. Status refers to the categories aggregation member, breeder or helper, and sex refers to male, female and immature juvenile. Significant effects are highlighted in bold fonts. 
excreted significantly less 11-ketotestosterone than male breeders (Fig. 1a, Table 2). Male helpers had intermediate excretion rates that did not differ significantly from those of male breeders and aggregation members (Fig. 1a, Table 2). There was no difference in 11-ketotestosterone excretion among male breeders and male helpers between the phases with and without eggs that had been produced in their respective family groups (i.e. no brood care effect; Fig. 2a, Table 3).

\subsection{Testosterone}

There was a significant overall effect of social status on testosterone excretion levels (Fig. 1b, Table 1). In pairwise comparisons among male breeders, male helpers and aggregation males, testosterone excretion rates of the different male categories did not differ significantly, but testosterone tended to be higher in aggregation males than in male breeders $(P=0.08$; Table 2$)$. A

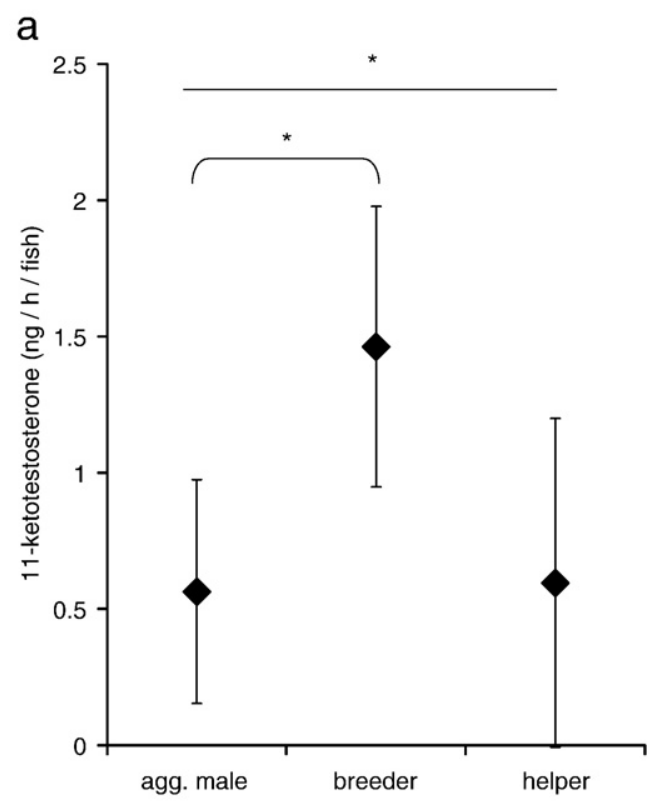

b
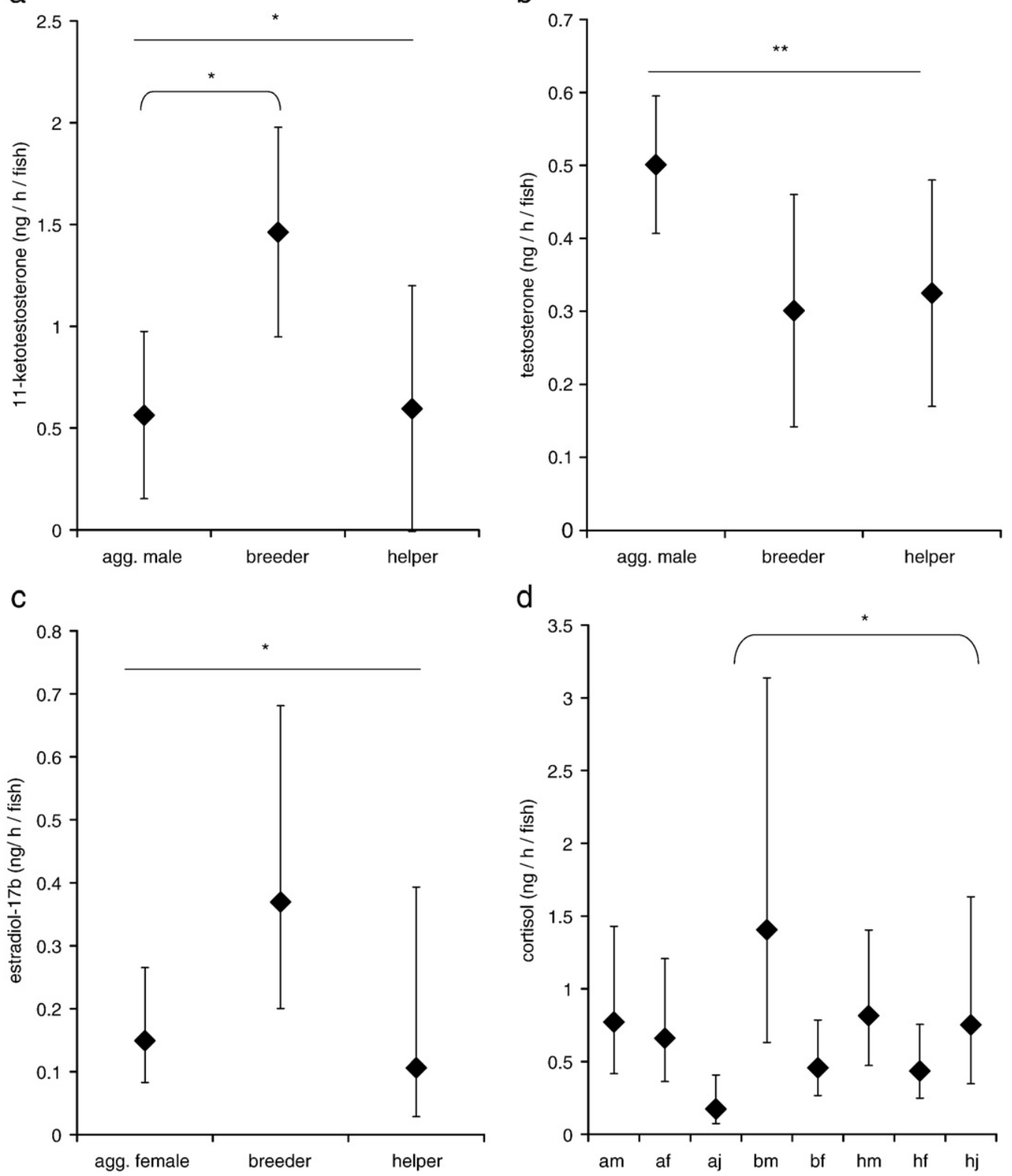

d

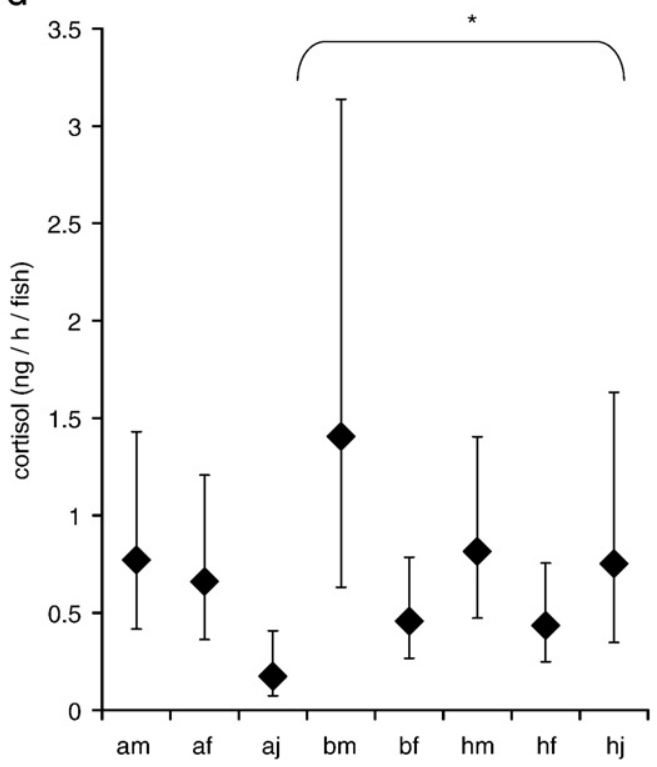

Fig. 1. Hormone excretion rates (in $\mathrm{ng} / \mathrm{h} /$ fish; means \pm S.E.) of fish with different social status: aggregation fish, breeder and helper (body mass considered as a covariate to account for potential body mass effects on hormone levels). Straight lines show overall effects of status, bent lines show effects of pairwise comparisons. a:11-ketotestosterone (only males, $n=23$ ). b: Testosterone (only males, $n=23$ ). c: Estradiol-17 $\beta$ (estradiol-17 $\beta$ levels were ln-transformed before analyses, means \pm S.E. are shown after back-transformation. Only females, $n=22$ ). d: Cortisol, values were separated for different social status categories and for different sexes (cortisol levels were $\ln$-transformed before analyses, means \pm S.E. are shown after back-transformation. All fish included, $n=62)$. For all statistical results see Tables 1,2 and 4. Abbreviations for $\mathrm{d}$ : $\mathrm{a}=$ aggregation fish, $\mathrm{b}=$ breeder, $\mathrm{h}=$ helper, $\mathrm{m}=$ male, $\mathrm{f}=$ female, $\mathrm{j}=$ juvenile. ${ }^{*}=$ significant at $P<0.05$, ** $=$ significant at $P<0.01$ (for cortisol results see Table 4). 
Table 2

ANCOVA table of pairwise comparisons of 11-ketotestosterone, testosterone and estradiol-17 $\beta$ excretion levels between different fish categories (estradiol-17 $\beta$ levels were $\ln$-transformed before analyses to meet the test conditions)

\begin{tabular}{|c|c|c|c|c|c|}
\hline Hormone & Status & Compared to status & Mean difference & Standard error & $P$ \\
\hline \multirow[t]{3}{*}{ 11-ketotestosterone } & Aggregation male & Breeder & -0.899 & 0.303 & 0.008 \\
\hline & Aggregation male & Helper & -0.032 & 0.362 & 0.930 \\
\hline & Breeder & Helper & 0.866 & 0.450 & 0.070 \\
\hline \multirow[t]{3}{*}{ Testosterone } & Aggregation male & Breeder & 0.200 & 0.083 & 0.027 \\
\hline & Aggregation male & Helper & 0.176 & 0.091 & 0.070 \\
\hline & Breeder & Helper & -0.024 & 0.135 & 0.861 \\
\hline \multirow[t]{3}{*}{ Estradiol-17 $\beta$} & Aggregation female & Breeder & -0.907 & 0.401 & 0.037 \\
\hline & Aggregation female & Helper & 0.341 & 0.680 & 0.622 \\
\hline & Breeder & Helper & 1.248 & 0.685 & 0.086 \\
\hline
\end{tabular}

Mass has been included as covariate to account for potential body mass effects on hormone levels. The $P$ values in multiple comparisons were adjusted according to the Benjamini and Hochberg adaptive approach to control for multiple testing [53]. After this correction, only the difference in 11-ketotestosterone between aggregation males and breeder males was significant (result in bold).

repeated measures ANOVA revealed no difference in testosterone excretion in male breeders and male helpers between phases with and without eggs that had been produced in the respective family groups (Fig. 2b, Table 3).

\subsection{Estradiol-17 $\beta$}

There was an overall significant effect of social status on estradiol-17 $\beta$ excretion levels, and also a significant interaction of status and mass (Fig. 1c, Table 1). In pairwise comparisons among female breeders, female helpers and female aggregation members, no significant difference was detected between the estradiol-17 $\beta$ excretion rates of these different categories of females (Table 2). In a comparison between phases with and without eggs that had been produced by the respective female breeders (brood care effect), there was no significant difference, both in female breeders and female helpers (Fig. 2c, Table 3).

\subsection{Cortisol}

There was a significant overall effect of sex on cortisol excretion rates (Table 1). The interaction between social status and sex was also significant (Table 1). Comparing 14 combinations of interest between the different fish categories (aggregation males, aggregation females, aggregation juveniles, male breeders, female breeders, male helpers, female helpers and juvenile helpers, see Table 4) significant differences in cortisol excretion rates were found only between aggregation juveniles and juvenile helpers (Fig. 1d, Table 4). In this pairwise comparison, only fish of same status or same sex were compared to each other, as only these comparisons are of ethological interest. In a repeated measures ANOVA there was no difference in cortisol excretion rates between the phases with and without eggs that had been produced in the respective family groups (i.e. no brood care effect; Fig. 2d, Table 3).

\subsection{Reaction to presented eggs}

In the test situation where a foreign clutch was presented to families outside of their own breeding period, no breeders and only three juvenile helpers showed brood care behaviour.
Comparing the cortisol excretion levels of these three eggcleaners with the five juveniles eating the presented eggs in the same situation, there was no significant difference (MannWhitney $U$ test: $Z=-0.745, P($ two-tailed $)=0.456)$.

\section{Discussion}

\subsection{Social status}

As expected, adult male non-breeding aggregation members showed significantly lower excretion rates of 11-ketotestosterone than male breeders, which reflects their different reproductive status. Sex steroid levels differ also between territorial and nonterritorial males of the cichlids O. mossambicus [45] and Astatotilapia burtoni [54]. There was also a significant influence of social status on testosterone excretion levels, but here aggregation males showed higher levels than male members of family groups (see Fig. 1b). These results suggest that aggregation males are physiologically capable to breed, but are sexually inactive because they lack a territory and therefore produce less 11-ketotestosterone. In fact, testosterone and 11-ketotestosterone have different roles in mating behaviour and brood care, in secondary sexual characters and in sperm production $[11,12]$.

For similar reasons we expected lower estradiol-17 $\beta$ excretion levels in aggregation females compared to female reproductive family members, which was confirmed by the general pattern described in Fig. 1c. Like in males, female aggregation members are reproductively inactive due to a lack of territory and mate, even though they are capable to breed often within very short periods ( 3 days; own observations) when provided with a territory and partner in lab experiments.

Adult helpers of both sexes exhibited intermediate steroid hormone levels between breeders and non-breeders (Fig. 1), which was reflected by a lack of significant differences in pairwise comparisons between the values of helpers and those of breeders and adult aggregation members, respectively (see also [5]). Fitzpatrick and co-workers [55] found a lower gonadal investment in $N$. pulcher male helpers than in male breeders in the wild and concluded that male helpers are reproductively suppressed. However, this interpretation is not confirmed by behavioural observations and genetic paternity analyses, which show a participation of 


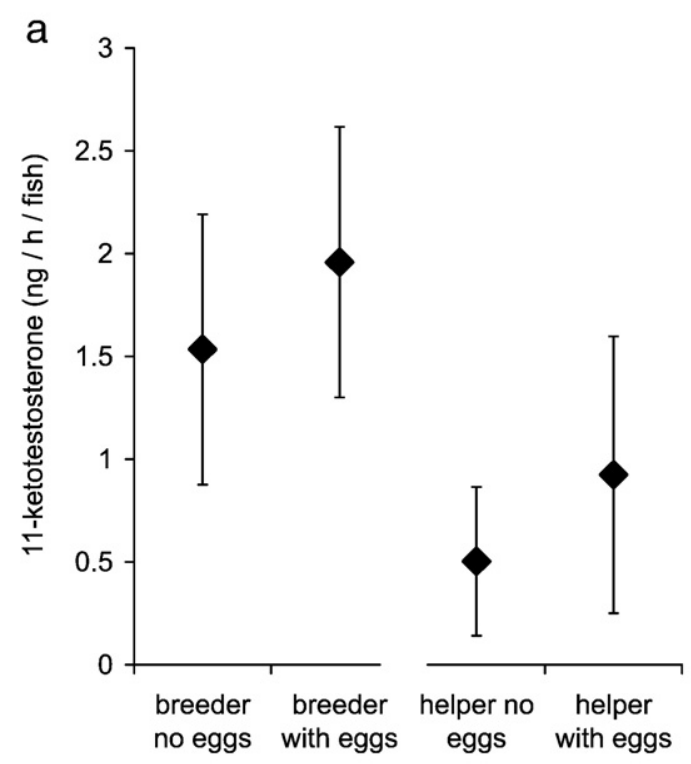

C

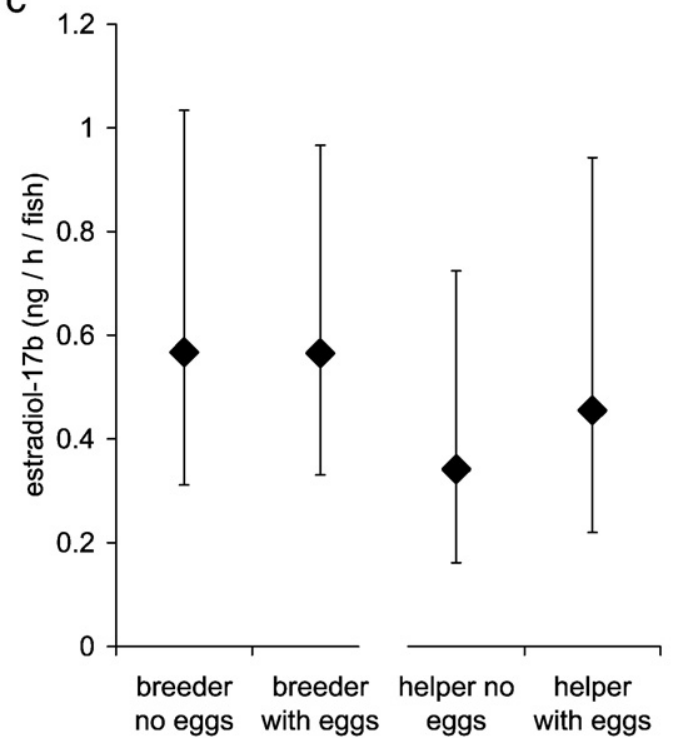

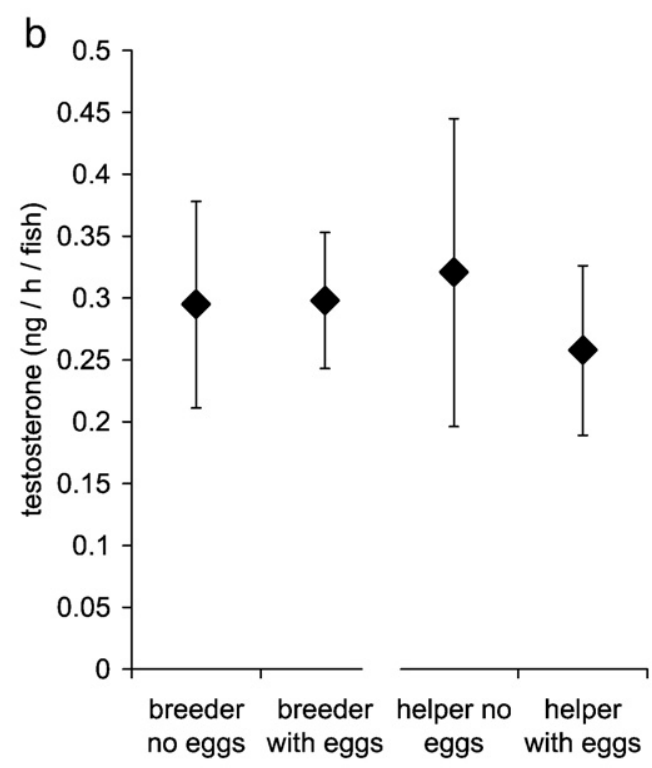

d

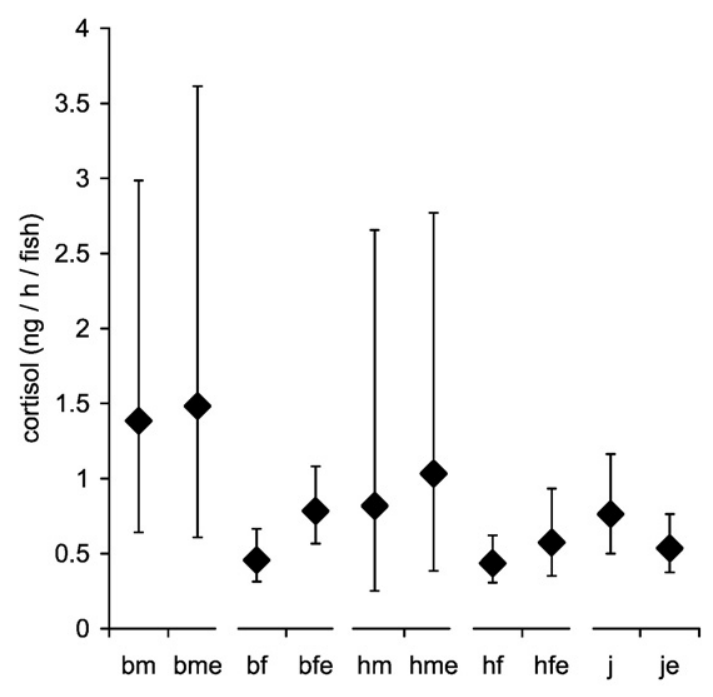

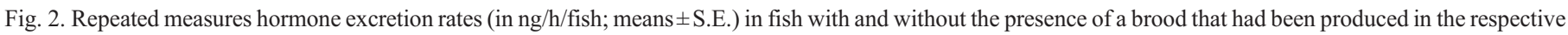

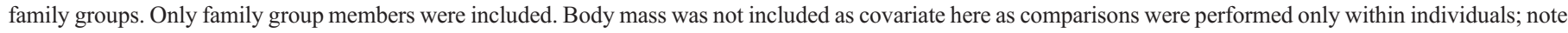

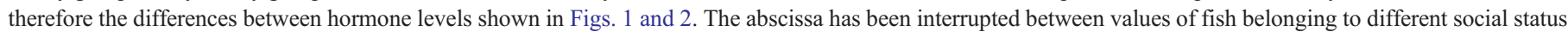

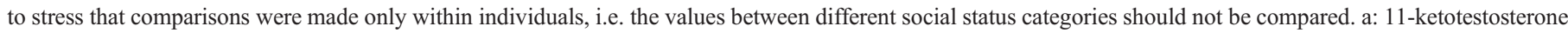

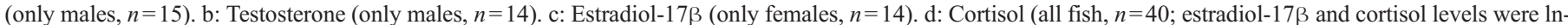

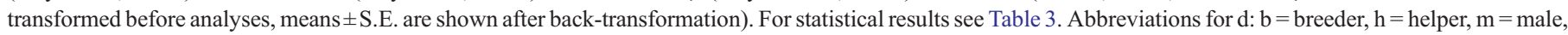
$\mathrm{f}=$ female, $\mathrm{j}=$ juvenile, $\mathrm{e}=$ with eggs.

N. pulcher helpers in reproduction $[38,39,56]$. In cooperatively breeding birds, helpers may show reduced levels of gonadal steroids [57], but also similar or even higher levels than breeders (in Florida scrub-jays, Aphelocoma coerulescens [58]). In general, the relationship between social status and androgens is complex and can vary over time and depend on the social stability of the group. In species where dominants suppress the reproduction of subordinates a difference in androgens is expected between dominant and subordinate group members $[57,59,60]$, while in species where subordinates can share in reproduction, dominants and subordinates usually do not differ in androgen levels [61].
As cortisol is a steroid hormone associated with stress, it can inhibit digestion, energy storage, growth and reproduction. In the short term, an elevation of cortisol leads to physiological and behavioural adaptations, while chronic elevations may lead to reproductive failure and disease $[62,63]$. In male meerkat helpers (Suricata suricatta) cortisol levels correlate positively with pupfeeding rates [64], suggesting a correlation between stress and helping behaviour. Furthermore, there is indication for a stressrelated suppression of reproduction in meerkat helpers [65]. In general, high levels of cortisol are correlated with stress in connection with social status, depending on the social system of 
Table 3

Repeated measures ANCOVA table of within individual differences between the phases with and without eggs ( $=$ brood) that had been produced in the respective family groups

\begin{tabular}{|c|c|c|c|c|}
\hline Hormone & Effect & $F$ & $d f$ & $P$ \\
\hline \multirow[t]{2}{*}{ 11-ketotestosterone } & Brood & 3.121 & 1 & 0.101 \\
\hline & Brood*status & 0.000 & 1 & 0.995 \\
\hline \multirow[t]{2}{*}{ Testosterone } & Brood & 2.338 & 1 & 0.152 \\
\hline & Brood*status & 2.796 & 1 & 0.12 \\
\hline \multirow{2}{*}{ Estradiol-17 $\beta$} & Brood & 0.507 & 1 & 0.489 \\
\hline & Brood*status & 0.528 & 1 & 0.481 \\
\hline \multirow[t]{3}{*}{ Cortisol } & Brood & 0.198 & 1 & 0.659 \\
\hline & Brood*status & 0.023 & 1 & 0.881 \\
\hline & Brood*sex & 1.309 & 2 & 0.283 \\
\hline
\end{tabular}

The effect of status (aggregation fish, breeder or helper) on hormone levels was included to test for a potential interaction. 11-ketotestosterone and testosterone hormone levels refer to male breeders and male helpers, estradiol-17 $\beta$ levels to female breeders and female helpers (estradiol-17 $\beta$ levels were ln-transformed before analyses in order to normalize the data) and cortisol levels refer to all family fish (cortisol levels were ln-transformed before analyses in order to normalize the data). For cortisol, also the effect of sex (male, female or juvenile) on hormone levels was included to test for a potential interaction. Mass was not considered as covariate, as comparisons were conducted only within individuals.

the species considered [66]. Mostly, in social systems with cooperative behaviour dominants have higher cortisol levels than subdominants [67]. In N. pulcher there is a strong hierarchy based on size, with the smallest helpers located at the end of the hierarchy. Furthermore small helpers show more direct brood care than large helpers [35]. As cooperative behaviour of helpers serves as an appeasing signal towards the breeders in this species [68], the increased brood care behaviour of small helpers result from their suppressed social status. Against expectation, we found no significant overall relationship between status (aggregation member, breeder, helper) and cortisol levels, suggesting that stress levels do not vary systematically between these different fish categories. However, as expected, juvenile helpers showed higher cortisol levels than juvenile aggregation members, which may reflect higher stress levels in subordinate helpers than in young aggregation members that are not exposed to a strong hierarchy. Therefore, in juvenile helpers there is a correlation between low social status, high cortisol levels and enhanced brood care behaviour (which is probably also an appeasement signal towards the breeders).

Furthermore, there was a significant effect of sex and of the interaction between status and sex on cortisol excretion levels. Males showed higher levels than females (Fig. 1d; differences were not significant in pairwise comparisons, however), particularly among family members. This indicates that male family members may experience more stress than female group members, which might be due to their role in territory defence, but also to the potential reproductive competition between them (see $[38,69]$ ).

\subsection{Brood care}

For both sexes, exogenous stimuli of the clutch are important for the maintenance and fine-tuning of brood care behaviour [35]. We measured hormone excretion in adult family members twice, once before and once after a brood that had been produced by the respective family groups. As expected, androgen levels of male breeders and male helpers did not change with appearance of a brood. In fact, in tropical littoral fish androgen levels have been found to show little fluctuation over time, as males of such species can reproduce more or less permanently and often with more than one female [12]. This is also true for $N$. pulcher [30,33,70]. It has been suggested that in birds paternal care is suppressed by high androgen levels [26], but this is not necessarily true for all bird species [71-73] and for fishes [14,74].

In female breeders the propensity to care for eggs depends more strongly on the stage in the breeding cycle than in male breeders, which may suggest a stronger role of hormones in the control of brood care behaviour in the female sex [35]. We expected a fluctuation of estradiol-17 $\beta$ excretion levels in female breeders due to regulatory processes involved in the breeding cycle, while female helpers should not show such fluctuating estradiol-17 $\beta$ levels as female helpers do usually not participate in reproduction $[33,39,75]$. Contrary to expectation, we found no differences in estradiol-17 $\beta$ excretion levels in female breeders between the egg stage and a period outside of the breeding cycle. Estradiol-17 $\beta$ excretion levels of female helpers also did not vary significantly between periods with and without a breeder's clutch tended by them. These results suggest a minor role of estradiol$17 \beta$ for the regulation of brood care behaviour in females.

As cortisol levels correlate positively with pup-feeding rates in male meerkats [64] we investigated the relationship between cortisol levels and brood care in N. pulcher breeders and helpers. In sexually immature helpers it is unlikely that sex steroids control brood care behaviour, but due to their submissive status cortisol could play a role. External stimuli have been shown to influence the regulation of brood care in helpers of this species, such as the rank position of a helper and its previous brood care experience [35]. However, we did not find a correlation between cortisol levels and brood care in this species, suggesting a minor

Table 4

ANCOVA table of pairwise comparisons of cortisol excretion levels between the different fish groups (cortisol levels were ln-transformed before analyses)

\begin{tabular}{llrlr}
\hline Status & $\begin{array}{l}\text { Compared } \\
\text { to status }\end{array}$ & $\begin{array}{l}\text { Mean } \\
\text { difference }\end{array}$ & $\begin{array}{l}\text { Standard } \\
\text { error }\end{array}$ & $P$ \\
\hline Aggregation male & Aggregation female & 0.155 & 0.366 & 0.675 \\
& Aggregation juvenile & 1.495 & 0.615 & 0.018 \\
& Breeder male & -0.600 & 0.391 & 0.131 \\
& Helper male & -0.055 & 0.441 & 0.902 \\
Aggregation female & Aggregation juvenile & 1.341 & 0.604 & 0.031 \\
& Breeder female & 0.368 & 0.374 & 0.330 \\
Aggregation juvenile & Helper female & 0.421 & 0.443 & 0.346 \\
Breeder male & Helper juvenile & -1.470 & 0.396 & $<\mathbf{0 . 0 0 1}$ \\
& Breeder female & 1.122 & 0.433 & 0.012 \\
Breeder female & Helper male & 0.545 & 0.532 & 0.310 \\
Helper male & Helper female & 0.054 & 0.404 & 0.895 \\
& Helper female & 0.631 & 0.366 & 0.091 \\
Helper female & Helper juvenile & 0.080 & 0.420 & 0.849 \\
\hline
\end{tabular}

Fourteen comparisons of interest were performed, and due to these multiple comparisons we adjusted with the Benjamini and Hochberg adaptive approach to control for multiple testing [53]. After this adjustment, only the result of the comparison between aggregation juveniles and helper juveniles was significant (result in bold). Mass was included as covariate to account for potential body mass effects on hormone excretion levels. 
role of cortisol for the regulation of brood care behaviour in $N$. pulcher. The above mentioned correlation between low social status, high cortisol levels and enhanced brood care behaviour in juvenile helpers does therefore not depend on the breeding cycle of the breeders.

\subsection{Some comments on the applied methodology}

\subsubsection{Cortisol}

A special concern when measuring excreted hormone levels from fish-holding water is the measurement of cortisol levels, as the measuring procedure itself may be a stressful event to the test animals. Therefore, the cortisol levels measured may represent a stress response of the fish rather than their hormonal baseline. In reef fishes (Chromis dimidiatus and Pseudanthias squamipinnis) it was observed that the cortisol levels measured in water correlated with the social situations of these fish, with higher excretion levels in more stressed fish [12]. Similar results were obtained in rainbow trout [42]. As we measured hormone excretion levels in the same way in all fish, any differences found are unlikely to be caused by the sampling method.

\subsubsection{Body mass}

In some analyses of this study we compared fish of different size classes, which is the reason why we included body mass as a covariate in the respective ANCOVAs. As the exact relationship between excreted hormone levels and body mass is not well understood, we performed the same range of analyses as shown in this paper also with hormone levels calculated per gram body mass, with body mass still included as a covariate in the ANCOVAs to correct for possible remaining mass effects. The results (not shown) did not differ strongly from the results presented here. In fact, no result changed from significant to non-significant or the other way round and there were no changes in the direction of the results. We conclude therefore that the results presented here are robust and that the effect of body mass has been accounted for satisfactorily (see also [37]).

\subsubsection{Hormone fractions}

The behavioural meaning of the different hormonal fractions (free fraction or conjugated fractions) is not yet known in detail. It was shown in several fish species that in socially challenging situations (like the presence of an intruder) the conjugated fractions increase more strongly than the free fraction (K. Hirschenhauser, personal communication). However, the role and the timing of release of the different fractions have to be investigated systematically in future studies. In the present study we included all fractions in the analysis in order not to miss any information. However, if we repeated the analysis separately for the free and the conjugated fractions of 11-ketotestosterone, we achieved similar results like for all fractions together (ANCOVA for effect of status on 11-ketotestosterone levels in aggregation males, male breeders and male helpers, body mass as covariate, $n=23$. All fractions: $F=6.08, P=0.027$; free fraction: $F=4.27$, $P=0.009$; conjugated fractions: $F=5.57, P=0.013$. Body mass did not show a significant effect on hormone levels in neither of the analyses).

\subsubsection{Variance}

It is common to find large standard errors in hormone measurements when sample sizes are relatively small (Figs. 1 and 2). The measurement of hormones in fish-holding water instead of plasma can possibly reduce the variation because excreted hormone levels represent an integrative measure over a time period of several hours, avoiding the typical hormonal fluctuations known from plasma. However, even if there is a strong correlation of repeatedly measured hormone levels within individuals (data not shown), the between individual variation remains high. This large variation is due to unknown causal factors that cannot be controlled. However, as this influence applies probably to all fish categories, the differences found between status groups have obviously not been completely obscured by these factors.

In summary, our results do not suggest a major regulating function of steroid hormones in the brood care behaviour of $N$. pulcher. However, sex steroid and cortisol excretion rates correlate partially with the social status of these fish, which can be explained mainly by differences in reproductive status and experienced social stress.

\section{Acknowledgements}

We thank R. Eggler, P. Stettler and E. Zwygart for technical assistance, and our colleagues from the Behavioural Ecology and Evolutionary Ecology Departments, University of Bern, for discussions on experimental design. We thank T. Oliveira and E. Couto for technical assistance during the hormonal analyses. I.M. Hamilton helped with the data analyses and he and B. Borg provided very useful comments on the manuscript.

The project was supported by the Swiss National Science Foundation (SNSF grants 3100-064396 and 3100A0-105626 to M.T. and SNSF grants 3234-069260.02/1 and PIOIA-103213 to N.B.), by the Stiftung zur Förderung der wissenschaftlichen Forschung an der Universität Bern to N.B., by The Pluriannual Program (R\&D Units 168 and 331) from the Portuguese Foundation for Science and Technology, through POCTI/FEDER respectively to A.V.M.C. and R.F.O. There were no conflicts of interest.

\section{References}

[1] Taborsky M. Sneakers, satellites and helpers - parasitic and cooperative behavior in fish reproduction. Adv Study Behav 1994;23:1-100.

[2] Taborsky M. The evolution of bourgeois, parasitic, and cooperative reproductive behaviors in fishes. J Heredity 2001;92:100-10.

[3] König WD, Dickinson JL. Ecology and evolution of cooperative breeding in birds. Cambridge: Cambridge University Press; 2004.

[4] Solomon NG, French JA. Cooperative breeding in mammals. Cambridge: Cambridge University Press; 1997.

[5] Oliveira RF, Hirschenhauser K, Canario AVM, Taborsky M. Androgen levels of reproductive competitors in a co-operatively breeding cichlid. J Fish Biol 2003;63:1615-20.

[6] Schoech SJ, Reynolds SJ, Boughton RK. Endocrinology. In: Koenig WD, Dickinson JL, editors. Ecology and evolution of cooperative breeding in birds. Cambridge: Cambridge University Press; 2004. p. 128-41.

[7] Wingfield JC, Hegner R, Lewis D. Circulating levels of luteinizing-hormone and steroid hormones in relation to social status in the cooperatively breeding white-browed sparrow weaver, Plocepasser mahali. J Zool 1991;225:43-58. 
[8] Ziegler TE, Wegner FH, Snowdon CT. Hormonal responses to parental and nonparental conditions in male cotton-top tamarins, Saguinus oedipus, a new world primate. Horm Behav 1996;30:287-97.

[9] Ziegler TE. Hormones associated with non-maternal infant care: a review of mammalian and avian studies. Folia Primatol 2000;71:6-21.

[10] Knapp R, Wingfield JC, Bass AH. Steroid hormones and paternal care in the plainfin midshipman fish (Porichthys notatus). Horm Behav 1999;35: 81-9.

[11] Liley NR, Stacey N. Hormones, pheromones and reproductive behavior in fish. In: Hoar WS, Randall DJ, Donaldson EM, editors. Fish physiology. New York: Academy Press; 1983. p. 1-63.

[12] Oliveira RF, Canario AVM, Bshary R. Hormones, behaviour and conservation of littoral fishes: current status and prospects for future research. In: Almada VC, Oliveira RF, Goncalves EJ, editors. Behaviour and conservation of littoral fishes. Lisbon: Istituto Superion de Psicologia Aplicada; 1999. p. 149-78.

[13] Pall MK, Mayer I, Borg B. Androgen and behavior in the male three-spined stickleback, Gasterosteus aculeatus II. Castration and 11-ketoandrostenedione effects on courtship and parental care during the nesting cycle. Horm Behav 2002;42:337-44.

[14] Ros AFH, Bruintjes R, Santos RS, Canario AVM, Oliveira RF. The role of androgens in the trade-off between territorial and parental behavior in the Azorean rock-pool blenny, Parablennius parvicornis. Horm Behav 2004;46: 491-7.

[15] Slijkhuis H, Deruiter AJH, Baggerman B, Bonga SEW. Parental fanning behavior and prolactin cell-activity in the male 3-spined stickleback Gasterosteus aculeatus L. Gen Comp Endocrinol 1984;54:297-307.

[16] Tacon P, Baroiller JF, Le Bail PY, Prunet P, Jalabert B. Effect of egg deprivation on sex steroids, gonadotropin, prolactin, and growth hormone profiles during the reproductive cycle of the mouthbrooding cichlid fish Oreochromis niloticus. Gen Comp Endocrinol 2000;117:54-65.

[17] Fiedler K. Die Wirkung von Prolactin auf das Verhalten des Lippfisches Crenilabrus ocellatus (Foskal). Zool Jahrb Abt Allg Zool Physiol Tiere 1962;69:609-20.

[18] Fiedler K, Bruss R, Christ H, Lotz-Zoller R. Behavioural effects of peptide hormones in fishes. In: Wuttke W, Weindl A, Vogt KH, Dries RR, editors. Brain and pituitary peptides. Basel: Karger; 1979. p. 65-70.

[19] Pall MK, Liljander M, Borg B. Prolactin diminishes courtship behaviour and stimulates fanning in nesting male three-spined sticklebacks, gasterosteus aculeatus. Behaviour 2004;141:1511-9.

[20] Brown RE. Hormones and paternal behavior in vertebrates. Am Zool 1985;25:895-910.

[21] Noble GK, Kumpf KF, Billings VN. The induction of brooding behavior in the Jewel fish. Endocrinology 1938;23:353-9.

[22] Oliveira RF, Almada VC, Goncalves EJ, Forsgren E, Canario AVM. Androgen levels and social interactions in breeding males of the peacock blenny. J Fish Biol 2001;58:897-908.

[23] Oliveira RF, Lopes M, Carneiro LA, Canario AVM. Watching fights raises fish hormone levels - cichlid fish wrestling for dominance induce an androgen surge in male spectators. Nature 2001;409:475.

[24] Oliveira RF. Social modulation of androgens in vertebrates: mechanisms and function. Adv Study Behav 2004;34:165-239.

[25] Oliveira RF. Neuroendocrine mechanisms of alternative reproductive tactics in fish. In: Sloman KA, Wilson RW, Balshine S, editors. Behaviour: interactions with physiology. New York: Elsevier; 2005.

[26] Wingfield JC, Hegner R, Dufty A, Ball G. The challenge hypothesis theoretical implications for patterns of testosterone secretion, mating systems and breeding strategies. Am Nat 1990;136:829-46.

[27] Duftner N, Sefc KM, Koblmuller S, Salzburger W, Taborsky M, Sturmbauer C. Parallel evolution of facial stripe patterns in the Neolamprologus brichardi/pulcher species complex endemic to Lake Tanganyika. Mol Phylogenet Evol 2007;45:706-15.

[28] Wisenden BD. Alloparental care in fishes. Rev Fish Biol Fish 1999;9:45-70.

[29] Balshine S, Leach B, Neat F, Reid H, Taborsky M, Werner N. Correlates of group size in a cooperatively breeding cichlid fish (Neolamprologus pulcher). Behav Ecol Sociobiol 2001;50:134-40.

[30] Dierkes P, Heg D, Taborsky M, Skubic E, Achmann R. Genetic relatedness in groups is sex-specific and declines with age of helpers in a cooperatively breeding cichlid. Ecol Lett 2005;8:968-75.
[31] Stiver KA, Dierkes P, Taborsky M, Gibbs HL, Balshine S. Relatedness and helping in fish: examining the theoretical predictions. Proc R Soc Lond B Biol Sci 2005;272:1593-9.

[32] Taborsky M, Limberger DA. Helpers in fish. Behav Ecol Sociobiol 1981;8: $143-5$.

[33] Taborsky M. Broodcare helpers in the cichlid fish Lamprologus brichardi their costs and benefits. Anim Behav 1984;32:1236-52.

[34] Taborsky M, Grantner A. Behavioural time-energy budgets of cooperatively breeding Neolamprologus pulcher (Pisces: Cichlidae). Anim Behav 1998;56:1375-82.

[35] von Siemens M. Broodcare and egg cannibalism by parents and helpers in Neolampologus brichardi (Pool 1986) (Pisces: Chichlidae): a study of behavioural mechanisms. Ethology 1990;84:60-80.

[36] Bender N, Taborsky M, Power DM. The role of prolactin in the regulation of brood care in the cooperatively breeding fish Neolamprologus pulcher. Submitted for publication.

[37] Bender N, Heg D, Hamilton IM, Bachar Z, Taborsky M, Oliveira RF. The relationship between social status, behaviour, growth and steroids in male helpers and breeders of a cooperatively breeding cichlid. Horm Behav 2006;50:173-82.

[38] Dierkes P, Taborsky M, Kohler U. Reproductive parasitism of broodcare helpers in a cooperatively breeding fish. Behav Ecol 1999;10:510-5.

[39] Heg D, Bergmuller R, Bonfils D, Otti O, Bachar Z, Burri R, et al. Cichlids do not adjust reproductive skew to the availability of independent breeding options. Behav Ecol 2006;17:419-29.

[40] Hirschenhauser K, Ros AFH, Carneiro LA, Oliveira T, Silva A, Canario $\mathrm{AVM}$, et al. Non-invasive hormone assessment from fish holding water. Adv Ethol 2002;37:139.

[41] Hirschenhauser K, Taborsky M, Oliveira T, Canario AVM, Oliveira RF. A test of the 'challenge hypothesis' in cichlid fish: simulated partner and territory intruder experiments. Anim Behav 2004;68:741-50.

[42] Ellis T, James JD, Stewart C, Scott AP. A non-invasive stress assay based upon measurement of free cortisol released into the water by rainbow trout. J Fish Biol 2004;65:1233-52.

[43] Scott AP, Sorensen P. Time-course of release of pheromonally active gonadal steroids and their conjugates by ovulatory goldfish. Gen Comp Endocrinol 1994;96:309-23.

[44] Vermeirssen ELM, Scott AP. Excretion of free and conjugated steroids in rainbow trout (Oncorhynchus mykiss): evidence for branchial excretion of the maturation-inducing steroid, 17,20 beta-dihydroxy-4-pregnen-3-one. Gen Comp Endocrinol 1996;101:180-94.

[45] Oliveira RF, Almada VC, Canario AVM. Social modulation of sex steroid concentrations in the urine of male cichlid fish Oreochromis mossambicus. Horm Behav 1996;30:2-12.

[46] Canario AVM, Scott AP. Conjugates of ovarian steroids, including 17a,20b-dihydroxy-4-pregnen-3-one (maturation-inducing steroid), accumulate in the urine of a marine teleost (plaice; Pleuronectes platessa). J Endocrinol 1989;127:R1-4.

[47] Guerreiro PM, Fuentes J, Canario AVM, Power DM. Calcium balance in sea bream (Sparus aurata): the effect of oestradiol-17 beta. J Endocrinol 2002;173:377-85.

[48] Scott AP, Mackenzie D, Stacey N. Endocrine changes during natural spawning in the white sucker, Catostomus commersoni.2. Steroid hormones. Gen Comp Endocrinol 1984;56:349-59.

[49] Kime DE, Manning NJ. Seasonal patterns of free and conjugated androgens in the brown trout Salmo trutta. Gen Comp Endocrinol 1982;48:222-31.

[50] Guerreiro PM, Rotllant J, Fuentes J, Power DM, Canario AV. Cortisol and parathyroid hormone-related peptide are reciprocally modulated by negative feedback. Gen Comp Endocrinol 2006;148:227-35.

[51] Moriwaki T, Kobayashi M, Aida K, Hanyu I. Changes in plasma gonadotropin and steroid-hormone levels during ovulation induced by HCG treatment in female goldfish. Nippon Suisan Gakkaishi 1991;57:41-3.

[52] Sokal RR, Rohlf FJ. Biometry: the principles and practice of statistics in biological research. New York: W.H. Freeman and Company; 1981.

[53] Benjamini Y, Hochberg Y. On the adaptive control of the false discovery rate in multiple testing with independent statistics. J Educ Behav Stat 2000;25:60-83. 
[54] Parikh VN, Clement TS, Fernald RD. Androgen level and male social status in the African cichlid, Astatotilapia burtoni. Behav Brain Res 2006;166: $291-5$.

[55] Fitzpatrick JL, Desjardins JK, Stiver KA, Montgomerie R, Balshine S. Male reproductive suppression in the cooperatively breeding fish Neolamprologus pulcher. Behav Ecol 2006;17:25-33.

[56] Dierkes P, Taborsky M, Achmann R. Multiple paternity in a cooperatively breeding fish. Behav Ecol Sociobiol in press.

[57] Reyer HU, Dittami JP, Hall MR. Avian helpers at the nest - are they psychologically castrated. Ethology 1986;71:216-28.

[58] Schoech SJ, Mumme RL, Wingfield JC. Delayed breeding in the cooperatively breeding Florida scrub-jay (Aphelocoma coerulescens): inhibition or the absence of stimulation? Behav Ecol Sociobiol 1996;39:77-90.

[59] Schoech SJ, Mumme RL, Moore M. Reproductive endocrinology and mechanisms of breeding inhibition in cooperatively breeding Florida scrub jays (Aphelocoma coerulescens). Condor 1991;93:354-64.

[60] Vleck CM, Brown JL. Testosterone and social and reproductive behaviour in Aphelocoma jays. Anim Behav 1999;58:943-51.

[61] Creel S, Creel NM, Mills MGL, Monfort SL. Rank and reproduction in cooperatively breeding African wild dogs: behavioral and endocrine correlates. Behav Ecol 1997;8:298-306.

[62] Creel S. Social dominance and stress hormones. Trends Ecol Evol 2001;16: 491-7.

[63] Goymann W, Wingfield JC. Allostatic load, social status, and stress hormones - the costs of social status matter. Horm Behav 2004;46:130.

[64] Carlson AA, Manser MB, Young AJ, et al. Cortisol levels are positively associated with pup-feeding rates in male meerkats. Proc R Soc Lond B Biol Sci 2006;273:571-7.

[65] Young AJ, Carlson AA, Monfort SL, Russell AF, Bennett NC, CluttonBrock T. Stress and the suppression of subordinate reproduction in cooperatively breeding meerkats. Proc Natl Acad Sci U S A 2006;103: 12005-10.
[66] Wingfield JC, Romero LM. Adrenocortical responses to stress and their modulation in free-living vertebrates. In: McEwan BS, Goodman HM, editors. Handbook of physiology: the endocrine system. New York: Oxford University Press; 2001. p. 211-34.

[67] Buchner AS, Sloman KA, Balshine S. The physiological effects of social status in the cooperatively breeding cichlid Neolamprologus pulcher J Fish Biol 2004;65:1080-95.

[68] Bergmuller R, Taborsky M. Experimental manipulation of helping in a cooperative breeder: helpers 'pay to stay' by pre-emptive appeasement Anim Behav 2005;69:19-28.

[69] Skubic E, Taborsky M, McNamara JM, Houston AI. When to parasitize? A dynamic optimization model of reproductive strategies in a cooperative breeder. J Theor Biol 2004;227:487-501.

[70] Limberger D. Pairs and harems in a cichlid fish, Lamprologus brichardi. Z Tierpsychol-J Comp Ethol 1983;62:115-44.

[71] Lynn SE, Hayward LS, Benowitz-Fredericks ZM, Wingfield JC. Behavioural insensitivity to supplementary testosterone during the parental phase in the chestnut-collared longspur, - Calcarius ornatus. Anim Behav 2002;63: 795-803.

[72] Lynn SE, Walker BG, Wingfield JC. A phylogenetically controlled test of hypotheses for behavioral insensitivity to testosterone in birds. Horm Behav 2005;47:170-7.

[73] Van Duyse E, Pinxten R, Eens M. Does testosterone affect the trade-off between investment in sexual/territorial behaviour and parental care in male great tits? Behaviour 2000;137:1503-15.

[74] Ros AFH, Canario AVM, Couto E, Zeilstra I, Oliveira RF. Endocrine correlates of intra-specific variation in the mating system of the St. Peter's fish (Sarotherodon galilaeus). Horm Behav 2003;44:365-73.

[75] Taborsky M. Breeder-helper conflict in a cichlid fish with broodcare helpers - an experimental analysis. Behaviour 1985;95:45-75. 